\title{
Iniciativas de las mujeres: emprendimiento y oportunidades en el espacio rural de Castilla y León
}

\author{
Milagros Alario Trigueros
}

Universidad de Valladolid. Departamento de Geografía alario@fyl.uva.es

\section{Erica Morales Prieto}

Universidad de Salamanca. Departamento de Geografía emoralesprieto@usal.es

\section{Resumen}

Desde hace décadas las mujeres han luchado por buscar su sitio en el mundo laboral. La opción del emprendimiento como alternativa a la precariedad y como posibilidad de encontrar nichos laborales acordes con su formación y necesidades se ha convertido en una alternativa en todos los espacios rurales. Se presenta el caso de Castilla y León, con espacios de fuerte ruralidad, como ejemplo para analizar estas dinámicas en territorios donde la lucha de las mujeres es aún más dura que la de otros colectivos y otros territorios. El objetivo del presente trabajo es conocer, en el marco de lo que supone el emprendimiento femenino en espacios rurales, las iniciativas económicas y sociales que las mujeres están poniendo en marcha en un medio rural que, a pesar de su abandono y decaimiento, puede aún explotar y aprovechar sus importantes recursos endógenos. Basándonos en el censo de población de 2011 y mediante un trabajo de campo, hemos realizado un diagnóstico de la situación laboral de las mujeres rurales para, a continuación, analizar las iniciativas de autoempleo estableciendo tipologías de emprendedoras y características de las iniciativas y destacando el perfil de las nuevas pobladoras y la orientación hacia actividades de servicios profesionales y turismo rural.

Palabras clave: mujer rural; empleo femenino; empleo rural; oportunidad; emprendimiento, Castilla y León 
Resum. Iniciatives de les dones: emprenedoria i oportunitats a l'espai rural de Castella i Lleó

Des de fa dècades les dones han lluitat per trobar el seu lloc en el món laboral. L'opció de l'emprenedoria com a alternativa a la precarietat i com la possibilitat de trobar nínxols laborals d'acord amb la seva formació i necessitats s'ha convertit en una alternativa en tots els espais rurals. Es presenta el cas de Castella i Lleó, amb espais amb forta ruralitat, com a exemple per analitzar aquestes dinàmiques en territoris on la lluita de les dones encara és més dura que la d'altres colllectius i en altres territoris. L'objectiu d'aquest treball és conèixer, en el marc del que suposa l'emprenedoria femenina en espais rurals, les iniciatives econòmiques i socials que les dones estan posant en marxa en un medi rural que, deixant de banda el seu abandonament i decadència, encara pot explotar i aprofitar-ne els importants recursos endògens. A partir del cens de la població l'any 2011 i mitjançant el treball de camp, hem fet un diagnòstic de la situació laboral de les dones rurals per, a continuació, analitzar les iniciatives d'autoocupació establint tipologies d'emprenedores i característiques de les iniciatives, i destacant el perfil de les noves pobladores i l'orientació envers activitats de serveis professionals i turisme rural.

Paraules clau: dona rural; ocupació femenina; ocupació rural; oportunitat; emprenedoria; Castella i Lleó

Résumé. Initiatives des femmes: entrepreneuriat et opportunités dans la zone rurale de Castille-et-Léon

Les femmes ont lutté pour se faire leur place dans le monde du travail depuis des décennies. L'option de l'entrepreneuriat et de l'emploi indépendant s'est convertie en alternative dans tous les espaces ruraux. Nous présentons le cas de la Castille-et-Léon, avec des espaces de forte ruralité, afin d'analyser ces dynamiques dans des territoires où la lutte des femmes est très spécialement intense face à d'autres collectifs et d'autres territoires. Le but du travail est de mieux connaître les initiatives économiques et sociales que les femmes mettent en place dans un milieu rural qui, malgré l'abandon et la décadence socio-économique, peut encore remonter et rationaliser l'utilisation des ressources endogènes. À partir du recensement de la population de 2011 et du travail sur le terrain, nous avons dressé un diagnostic de la situation du travail des femmes rurales pour, ensuite, analyser les initiatives d'auto emploi en établissant des typologies d'entrepreneuses et des caractéristiques des initiatives, en soulignant le profil des nouvelles habitantes et l'orientation vers des activités de services professionnels et de tourisme rural.

Mots-clés: femme rurale; emploi féminin; emploi rural; opportunité; entreprise; Castilleet-Léon

Abstract. Women's initiatives: entrepreneurship and opportunities in the rural areas of Castile and Leon

For decades women have struggled to find their place in the labour market. The option of promoting entrepreneurship as an alternative to the precariousness and as a possibility of finding labour niches in accordance with their skills and needs has become a real alternative in all rural areas. We analyze here the case of Castile and Leon, with large rural areas, as an example to understand these dynamics in territories where women's struggle is even harder than in other groups or in other territories. The objective of this article is to see, within the framework of what supposes female entrepreneurship in rural areas, the economic and social initiatives that women are launching in the rural environment. In this context, despite its abandonment and decay, they can still exploit and take advantage 
of major endogenous resources. Based on the 2011 population census and through field work, we have carried out a diagnosis of the situation of the rural women's workforce; in a second stage, we analyze self-employment initiatives and establish the typologies of entrepreneurs and the characteristics of their initiatives, highlighting the profile of the new inhabitants and their orientation towards professional services and rural tourism activities.

Keywords: rural woman; feminine employment; rural employment; opportunity; Castile and Leon

\section{Sumario}

1. El emprendimiento en España: la singularidad de los espacios rurales

2. El emprendimiento rural: el papel de las mujeres
3. El medio rural de Castilla y León:

la estrechez del mercado laboral y las dificultades de las mujeres

4. Conclusiones

Referencias bibliográficas

\section{El emprendimiento en España: la singularidad de los espacios rurales}

El siglo xxi es el siglo del emprendimiento. Existe una gran cantidad de literatura publicada centrada en este concepto y en el espíritu emprendedor, pero todavía no ha surgido una teoría general de este concepto, aunque es cierto que la teoría de desarrollo económico (1911) es la primera que habla del espíritu emprendedor como el motor primario de desarrollo económico relacionado con la innovación. Según esta teoría, emprendedora es la persona que crea las nuevas combinaciones de producción, busca nuevos mercados y está dispuesta a asumir riesgos y a organizar los mecanismos sociales y económicos que están a su disposición aprovechándose de las oportunidades del mercado y de los responsables político-económicos (Lordkipanidze et al., 2005: 788-789).

A partir de las teorías que apoyan la relación directa entre crecimiento económico y desarrollo, todas las instancias - la Unión Europea, los gobiernos nacionales, los responsables autonómicos e, incluso, los locales - han apostado por el emprendimiento como una alternativa eficaz para impulsar el crecimiento y el trabajo. Una tendencia seguida en mucha mayor medida en los últimos años, cuando la crisis ha reducido las oportunidades tradicionales de empleo y las sociedades más desarrolladas se han enfrentado al terrible problema de un paro creciente, de magnitud desconocida en las últimas décadas. Se puede entender el emprendimiento como una "opción elegida" o "por necesidad», como una vía de autoempleo creciente en los entornos más castigados por la crisis, como los países del sur de Europa (Ruiz Navarro et al., 2013).

Algunos autores hablan de espíritu emprendedor y definen a los nuevos empresarios como individuos que identifican, descubren y explotan nuevas oportunidades en relación con el espacio en el que se desarrollan. Contex- 
tos cambiantes que justifican que autores como Baumgartner identifiquen hasta siete diferentes tipos de espíritu emprendedor ${ }^{1}$ con perspectivas distintas, aunque todos ellos parten de que las formas de capital social promueven el desarrollo endógeno o local directamente o, al menos, indirectamente, lo que contribuye a favorecer las actividades económicas en un entorno concreto (Baumgartner et al., 2013: 1102-1103).

El Proyecto GEM (Global Entrepreneurship Monitor) analiza desde finales del siglo pasado las iniciativas emprendedoras a escala de estados, y por comunidades autónomas en el caso español, lo que nos permite obtener una panorámica de conjunto como marco de referencia para el posterior estudio del caso de Castilla y León. Según el informe de 2014, más de una quinta parte de la población entre 18 y 64 años ve una oportunidad en el emprendimiento y más de la mitad considera que emprender es una buena opción profesional en España, lo que supone un descenso de casi 10 puntos respecto a 2006, situación anterior al inicio de la crisis económica. Sin embargo, se ha incrementado ligeramente el volumen de emprendedores que lo son impulsados por la falta de opciones en el mercado laboral $-29,8 \%$ en $2014-$, y que han duplicado su peso respecto a 2007. El perfil predominante es el de personas entre 35 y 44 años, aunque la crisis ha incrementado el peso del colectivo entre 45 y 54 años. Son ligeramente dominantes los hombres sobre las mujeres - 6 de cada 10-, aunque su participación tiende a ser más equitativa en el caso de los emprendedores potenciales de 2014, y, en general, predomina la formación media y superior. Los sectores de actividad a los que se orientan mayoritariamente las personas emprendedoras en España están relacionados con los servicios al consumo $(42,5 \%)$ y a la producción $(22 \%)$.

Por lo que respecta a la situación de Castilla y León en este contexto global, sus indicadores de emprendimiento están significativamente por debajo de la media nacional (GEM España, 2014). El volumen de personas con intención de emprender está 2,5 puntos por debajo del conjunto en 2013. Igual que en el resto del país, entre los nuevos emprendedores casi una cuarta parte ha basado su opción en la necesidad de buscar su propio trabajo ante la mala situación del mercado laboral. Llegan al emprendimiento después de otras actividades y con un buen nivel de formación, con una edad media de 37 años y casi la mitad con estudios superiores y formación específica (GEM Castilla y León, 2013). De hecho, en 2015, según los datos aportados por el Registro General de la Tesorería de la Seguridad Social, los trabajadores autónomos en el conjunto de los ocupados, que podemos asimilar con personas emprendedoras, constituyen algo más del 23\% del total, con una presencia especial en actividades de servicios comerciales, hostelería y servicios a la población, aunque también alcanzan un peso significativo en otras áreas, como el transporte, la construcción y la reparación.

1. Espíritu emprendedor en empresas pequeñas y de tamaño mediano (PYME), espíritu emprendedor en el sector de producto agroalimenticio, espíritu emprendedor inmigrante, espíritu emprendedor social, espíritu emprendedor de comunidad, espíritu emprendedor corporativo y espíritu emprendedor público. 
Aunque, al igual que en el conjunto de España, las mujeres representan una parte minoritaria de las iniciativas emprendedoras existentes, es muy significativo el incremento de su participación en las nuevas iniciativas, pues superan en más de un punto a los varones en 2013 (GEM Castilla y León, 2013: 37). Quizás tenga algo que ver el apoyo que desde la Administración se está dando al emprendimiento rural, muy especialmente a las mujeres, objetivo preferente de estas medidas bien valoradas por las afectadas con un 3,1 sobre 5 (GEM, Castilla y León 2013: 26).

\section{El emprendimiento rural: el papel de las mujeres}

Los cambios en las funciones asignadas a los espacios rurales y, consecuentemente, en las estrategias seguidas por las políticas rurales para su desarrollo han convertido a la figura de la persona emprendedora en un elemento clave en su dinamismo económico.

En palabras de Sampedro y Camarero, la actividad emprendedora marcó el principio del fin del modelo capitalista tradicional que ha transformando la estructura económica y social de las últimas décadas fundamentalmente en el medio rural, y se considera, incluso, la figura que mejor ejemplifica esa nueva imagen de un medio rural lleno de nuevos recursos y posibilidades (Sampedro y Camarero, 2007: 123). De esta manera y según afirma Baptiste:

[...] el espíritu emprendedor es el motor primario de desarrollo económico con la innovación como elemento central [...] donde se pueden llevar a cabo nuevas combinaciones como pueden ser la introducción de nuevos métodos de producción, la apertura de nuevos mercados, la utilización de nuevas fuentes de suministro, nuevas oportunidades industriales... (Baptiste en Lordkipanidze et al., 2005: 788)

De este modo, el fomento del emprendimiento se ha convertido en una opción clave de los programas de incentivación económica, desarrollo rural e incluso igualdad de oportunidades, con lo que se alcanza el objetivo descrito por Bristol, que afirma que el espíritu emprendedor debe tener como objetivo integrar el desarrollo rural y hacerlo sostenible (Bristol et al., 2001 en Andersson et al.: 34).

Las especiales dificultades de los espacios rurales para poner en marcha proyectos de gran envergadura en lo que se refiere a la creación de trabajo asalariado sitúan a la opción del emprendimiento como una de las favoritas para la creación de trabajo remunerado. Así, en los espacios rurales de Castilla y León la tasa de trabajadores autónomos supera el $40 \%$, incluso sin contar los trabajadores agrarios que figuran en el régimen especial de la seguridad social.

El emprendimiento se ha convertido en el motor de desarrollo económico en las áreas rurales (Lordkipanidze, Brezet y Backman, 2005) impulsado por las administraciones. Se han puesto en marcha nuevas actividades económicas apoyadas por la política estructural de la Unión Europea y sus fondos, pero también por equivalentes nacionales y otros fondos y medidas, con el objeto 
de promover nuevas iniciativas empresariales pero también el estímulo del espíritu emprendedor, la innovación, la cooperación, la comercialización y el desarrollo de una imagen de marca (Garrod et al., 2006, Oliver y Jenkins, 2003 en Andersson et al., 2009).

Se ha utilizado, de manera especial, como una herramienta para solventar las debilidades del mercado de trabajo rural dirigido a mujeres y jóvenes. Por ello, desde las políticas de desarrollo rural se ha apostado por fomentar la promoción y apoyar las iniciativas empresariales impulsadas por mujeres con el objetivo no solo de crear alternativas laborales al medio rural, sino también de aumentar su participación laboral y, consecuentemente, conseguir una mayor diversificación de la economía rural (Aguilasocho, 2006). Sin embargo, en el alcance y desarrollo de estas nuevas oportunidades de empleo persisten las desigualdades entre varones y mujeres (MARM, 2011).

Las políticas de desarrollo rural han apoyado y fomentado la utilización del emprendimiento como una herramienta para solventar las debilidades del mercado de trabajo rural. Además de incentivar el autoempleo, que ha permitido generar nuevos puestos de trabajo, contribuye al incremento de la participación laboral de las mujeres en el medio rural y a mejorar su calidad de vida personal y la del conjunto de los espacios rurales al facilitar logros profesionales, independencia, satisfacción del trabajo y expectativas de beneficio personal (Lordkipanidze et al., 2005: 789).

La primera edición del informe "Mujer y desafío emprendedor en España» señalaba que solo el 8,2\% de los proyectos de 2009 fueron desarrollados por mujeres, lo que muestra la brecha de género en la actividad emprendedora (Rodríguez et al., 2013), ya que las mujeres han tenido siempre mayores problemas para poder emprender, entre otras razones por sus mayores dificultades para la obtención de financiación o «acceso al crédito, un bajo nivel de internacionalización de la actividad emprendedora, un mayor retraso en la toma de decisión de emprender y un menor nivel de autoconfianza» (Ruiz et al., 2011 en Rodríguez et al., 2013). Al mismo tiempo, las mujeres se encuentran con otro tipo de dificultades relacionadas con la dependencia familiar y el desarrollo del trabajo empresarial al mismo tiempo que el familiar, a lo que hay que sumar sus actividades personales. Pese a estas dificultades, las mujeres deciden emprender por motivos variados de tipo intrínseco, como la necesidad de logro, autorrealización e independencia, o motivos transcendentales, como el anhelo de compaginar tareas empresariales con la familia y el hogar (Rodríguez et al., 2013).

La labor no resulta fácil para las empresarias rurales, ya que, a pesar de los discursos institucionales, aunque se aprecia un incremento de las empresarias que no emplean a personal, el colectivo de empresarias que tienen trabajadores a su cargo ha perdido peso en la estructura socioprofesional. Es decir, se ha potenciado el autoempleo pero no se ha promovido el desarrollo rural. Este fenómeno tiene mucho que ver con el tipo de empresas y los modelos empresariales de las mujeres rurales.

Según el estudio "Medio rural: trabajando en femenino», se puede hablar de emprendimiento familiar, profesional o estacional. El primero de ellos, el 
emprendimiento familiar, está promovido por una decisión familiar motivada por la falta de oportunidades laborales en la zona y el deseo de las mujeres de no dedicarse únicamente al trabajo doméstico y al cuidado de los hijos. Se trata, por lo general, de negocios familiares gestionados por mujeres y promovidos inicialmente por sus parejas. Es un tipo de emprendimiento que representa un complemento a la renta familiar, que genera beneficios económicos pero no con la rentabilidad suficiente como para cubrir la independencia económica de una persona; el emprendimiento profesional está protagonizado por mujeres con formación superior que recurren al autoempleo para suplir las dificultades que encuentran en el mercado laboral para conseguir un empleo con el que desarrollarse profesionalmente, y para superar las dificultades de conciliar la vida laboral y familiar aprovechando los recursos y las potencialidades del territorio. Las mujeres que optan por este tipo de emprendimiento tratan de flexibilizar la jornada laboral adaptándola a las necesidades familiares para aportar recursos a la economía familiar de forma directa y consolidar una identidad profesional acorde a su cualificación y sus expectativas de desarrollo personal. En tercer lugar está el emprendimiento estacional para aprovechar las oportunidades económicas que ofrece un territorio en determinados periodos del año y explotar la multifuncionalidad de los espacios rurales a través de la revalorización de los recursos naturales y culturales del territorio, o la transformación y comercialización de sus productos. De este modo, constituye un complemento a la renta familiar que puede compaginarse con la actividad agraria en los periodos de menor carga laboral o puede ser realizado por miembros de la familia - generalmente mujeres - que no colaboran de forma continua en la explotación familiar (MARM, 2013: 39-41).

La opción del emprendimiento tiene, por tanto, unas consecuencias ambivalentes, ya que, si por un lado ayuda a la inserción laboral de las mujeres rurales y apoya la dinamización económica de esos espacios, por otro lado sigue lastrando su trabajo con problemas de subsidariedad, falta de competitividad y menor capacidad de crecimiento, ya que, como señalan Sampedro y Camarero:

[...] en general, los negocios dirigidos por mujeres son más pequeños, crean menos empleo, usan más trabajo familiar no pagado, emplean más mujeres, se concentran en un estrecho abanico de sectores tradicionalmente feminizados, tienen un menor nivel de ventas, reciben menos créditos, están con mayor frecuencia situados en el propio domicilio, tienen menos probabilidad de convertirse en empresas mayores, y más probabilidad de desaparecer, que los negocios creados por varones. (Grasmuck y Espinal, 2000) (Sampedro y Camarero 2007: 125)

Desde el punto de vista sectorial, el emprendimiento rural femenino se encuentra muy condicionado por las limitaciones de un mercado laboral con pocas opciones, lo que, junto a los estereotipos de género y la potencialidad derivada de la coyuntura reciente, ha orientado la inversión masivamente a actividades de servicios y, en particular, al turismo rural, de forma que se 
aprecia una excesiva focalización en el turismo rural de las iniciativas auxiliadas por fondos públicos: «un estudio realizado en 1999 en diez comarcas rurales españolas ponía de manifiesto que en siete de ellas el 70\% de las inversiones de las mujeres eran absorbidas por el turismo rural» (Langreo, 2000, en Sampedro y Camarero 2007: 126).

Todos los problemas indicados hasta aquí afectan a las mujeres que habitan los espacios rurales de Castilla y León, con el agravante añadido de las limitaciones que introduce un medio rural con fuerte atonía demográfica y económica, intenso envejecimiento y una enorme dispersión de la población en entidades de muy pequeño tamaño. Características, todas, que condicionan un mercado laboral muy estrecho y con escasas oportunidades para las mujeres que quieran orientar su vida profesional fuera de las actividades dominantes: las agrarias y los servicios (Alario, 2011).

\section{El medio rural de Castilla y León: la estrechez del mercado laboral y las dificultades de las mujeres}

Castilla y León es una comunidad donde el peso de lo rural es mucho mayor que en el resto del Estado. Mientras en el conjunto de España tan solo el 6\% de la población reside en municipios menores de dos mil habitantes, que podemos considerar rurales en sentido estricto, en Castilla y León ese porcentaje supera la cuarta parte.

Este elevado peso de la población rural podría hacernos pensar en un medio dinámico que retiene población gracias a su crecimiento económico y demográfico. Nada más lejos de la realidad; las 666.380 personas residentes en este espacio rural se distribuyen entre más de seis mil pueblos (administrativamente dos mil municipios) cuya dinámica en el último medio siglo ha estado marcada por la regresión demográfica, el envejecimiento y un éxodo selectivo que les ha hecho perder una parte fundamental de su población: los jóvenes y, de forma especial, las mujeres. De esta forma, si la masculinización es la marca característica de la mayor parte de los espacios rurales españoles - 1,09 hombres por cada mujer - es mayor en el caso de Castilla y León — 1,13 — y más elevada, aún, en el grupo de mujeres jóvenes - 1,23 hombres por cada mujer en el colectivo de entre 25 y 55 años.

Las jóvenes son las que más han sufrido las consecuencias de un proceso de especialización productiva que, basado en la tecnificación y la agricultura familiar de secano, las ha expulsado de la actividad agraria. La práctica monoespecialización agraria de estos espacios ha dificultado enormemente la inserción laboral de las mujeres rurales, relegadas, durante mucho tiempo, al papel de ayudas familiares en las explotaciones o, como mucho, al trabajo, no siempre visible, en los escasos servicios de atención básicos que quedaron en estos pueblos tras el éxodo rural: los bares y las pequeñas tiendas. Las últimas décadas han puesto de manifiesto, sin embargo, significativos cambios en este panorama con avances sustanciales en la tasa de actividad y en la normalización laboral de las mujeres en los espacios rurales regionales. 


\subsection{Las limitaciones de las fuentes estadísticas para el análisis de la actividad femenina}

La valoración de la situación de las mujeres en el mercado laboral requiere, sin duda, un contexto de análisis cuantitativo que permita evaluar la magnitud de los procesos estudiados. El trabajo sobre espacios rurales introduce una dificultad derivada de la escala local a la que obliga el análisis, que está mal recogida en la mayoría de las fuentes habituales sobre el mercado laboral. Como única fuente que cruza el criterio de tipos de espacios y las características sociodemográficas y económicas de la población (residencia rural, edad, sexo, nacionalidad y actividad), hemos utilizado los microdatos del Censo de Población de 2011, que nos han permitido realizar un primer diagnóstico cuantitativo de base sobre las dinámicas y características de inserción laboral de las residentes en municipios rurales de menos de dos mil habitantes de Castilla y León entre el periodo 2000-2010, introduciendo la categoría de nacionalidad.

Sin embargo, como han puesto de manifiesto innumerables investigadoras, las metodologías cuantitativas deben ser complementadas ineludiblemente con métodos cualitativos que nos permitan acercar a la realidad compleja de las estrategias desplegadas por las mujeres para compaginar sus roles reproductivos y productivos, además de comprender dinámicas personales y grupales complejas (Sabaté et al., 2010; Bayllina, M., 2004).

Apostamos, pues, por una metodología mixta, cuantitativa y cualitativa, que nos permita obtener una mejor aproximación al tema del papel de las mujeres neorrurales en el emprendimiento (Karsten y Meertens, 1992).

Por ello, se han realizado 144 encuestas, en modelo de cuestionario semiestructurado con preguntas abiertas y otras de respuesta múltiple, y 30 entrevistas personales que han permitido valorar los planteamientos y las razones que inducen a los nuevos pobladores a trasladarse al medio rural e iniciar nuevas opciones de vida y trabajo en el caso de los neorrurales, es decir, a los que se han instalado en municipios eminentemente rurales, de menos de dos mil habitantes fuera de la influencia urbana.

De los cuestionarios distribuidos por un total 52 entidades municipales de Castilla y León (figura 1), 73 corresponden a mujeres neorrurales y 14 son emprendedoras (Morales, 2015).

La distribución de las repuestas nos permite tener una representación al mismo tiempo de los espacios elegidos por las mujeres encuestadas, que no apuestan por municipios próximos a las ciudades sino por espacios con un fuerte carácter rural de la penillanura zamorano-salmantina, Montaña Palentina, Nordeste de Segovia o pequeños enclaves en Valladolid, León, Segovia y Soria.

\subsection{La presencia de las mujeres rurales en el mercado laboral}

En constante proceso de avance, aunque siempre a menor ritmo que en espacios urbanos, las mujeres rurales de Castilla y León han ido ganando posiciones en el mercado laboral, lo que se manifiesta en el incremento de la tasa de 


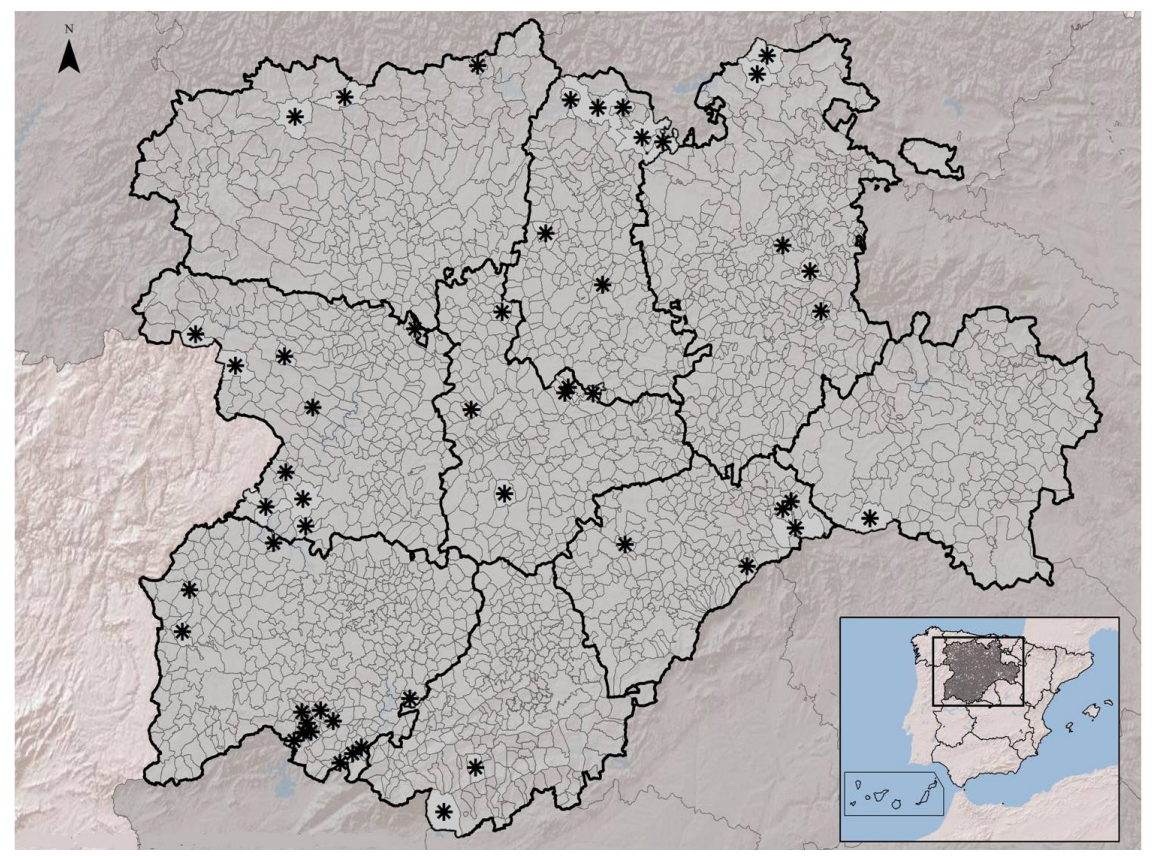

Figura 1. Distribución de las entrevistas y cuestionarios respondidos por mujeres neorrurales.

Fuente: Encuestas personales. Elaboración: E. Morales.

actividad femenina, que ha crecido 12 puntos en la última década y ha pasado del $28 \%$ al $40 \%$ entre los datos censales de 2001 y 2011 (figuras 2 y 3). Es significativa la aportación que suponen las mujeres extranjeras a este crecimiento de la presencia femenina en los mercados de trabajo rurales, especialmente en el grupo de adultas entre 25 y 45 años, que incluye a las inmigrantes que llegan con el objetivo de trabajar en actividades regladas.

Aunque hay aún una diferencia significativa entre la tasa de actividad femenina y la masculina, derivada fundamentalmente de la existente en los mayores de 45 años, que es donde se incrementa la participación en la actividad, y donde aún pesan comportamientos más tradicionales entre las mujeres. Este hecho se manifiesta mucho más claramente en la práctica inexistencia de actividad en el grupo de mayores de 65 años, fundamental en la población femenina rural. De esta forma, «el binomio ruralidad/feminización del envejecimiento marca, pues, una situación claramente desfavorable en lo que se refiere a la inserción laboral de las mujeres rurales» (Alario, 2011: 84).

Por el contrario, los grupos de mujeres adultas superan tasas del $80 \%$, lo que indica un proceso de normalización en la relación de las mujeres con el trabajo. Frente a lo que ocurría una década atrás, las mujeres rurales han interiorizado la necesidad de trabajar fuera del hogar como una forma normalizada 


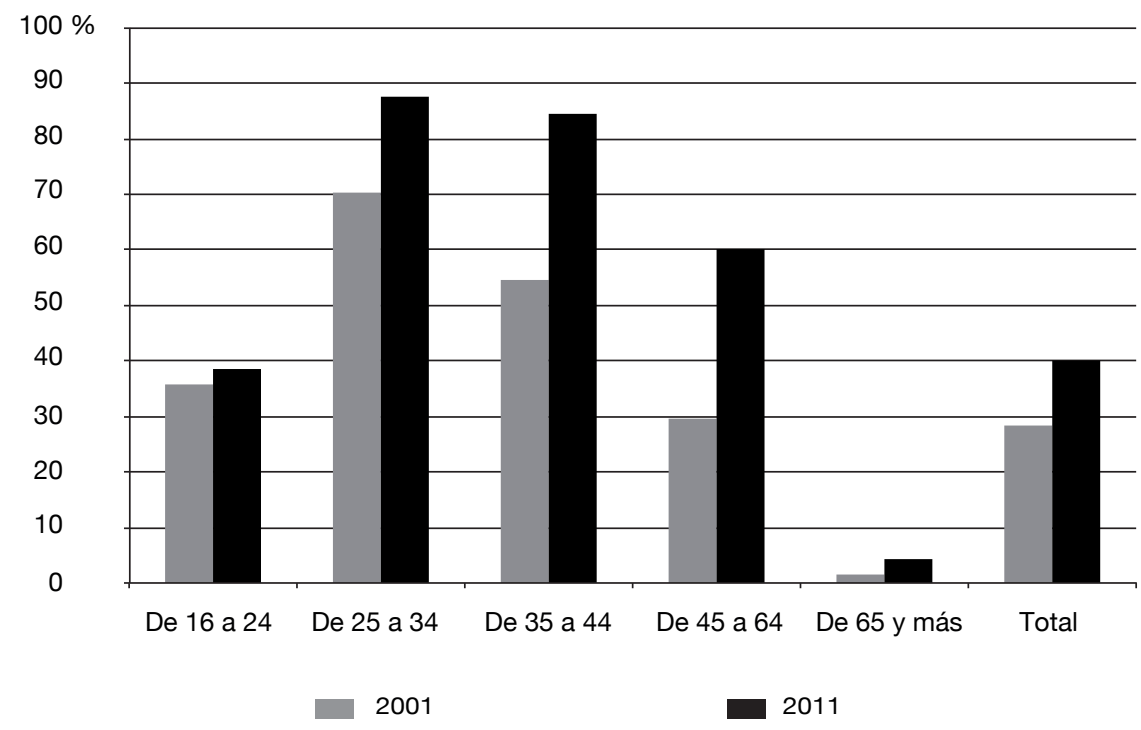

Figura 2. Tasa de actividad femenina en espacios rurales. Castilla y León, 2001-2011. Fuente: INE, Censos de Población 2001-2011. Elaboración: M. Alario.

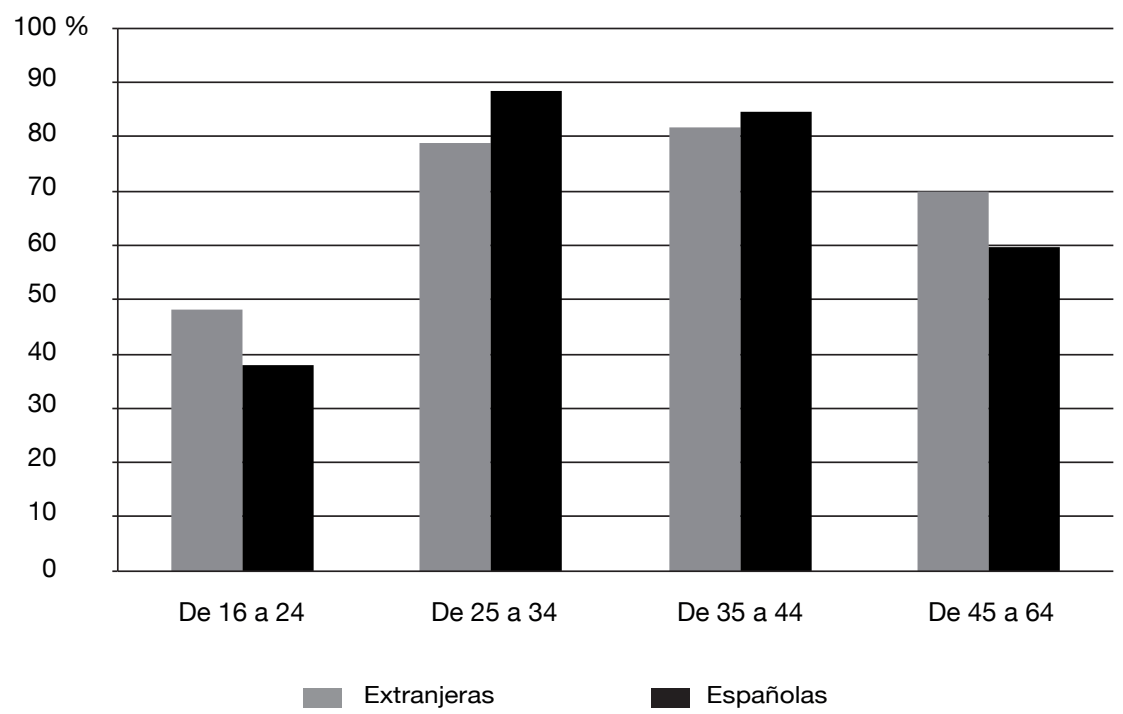

Figura 3. Tasa de actividad femenina por nacionalidad rural. Castilla y León, 2011. Fuente: INE, Censo de Población 2011, microdatos. Elaboración: M. Alario. 
de vida. Si bien el 43\% de las ocupadas señalan razones económicas e instrumentales como prioritarias, un 35\% aducen razones relacionadas con el placer de ejercer su profesión, ser independientes económicamente o el gusto por el trabajo en sí mismo, es decir, razones vinculadas a una opción emancipatoria del trabajo femenino. En conjunto, las razones de las mujeres para trabajar son muy similares a las de los varones (Alario, 2011).

Sin embargo, aún no podemos hablar de igualdad por los fuertes condicionantes derivados del mantenimiento de roles tradicionales de cuidado familiar sobre el peso de las decisiones laborales de muchas mujeres, particularmente las rurales.

La relación de las mujeres rurales con el mercado laboral es, cuando menos, tormentosa. Sus tasas de paro son muy superiores a las de sus vecinos varones (32\% las activas frente a poco más del $20 \%$ en varones), y este problema es especialmente grave para las jóvenes y las mujeres con titulación superior, con dificultades añadidas para insertarse en un mercado laboral estrecho y precario. El paro siempre ha sido una de las formas de iniciar la relación de las mujeres con el mercado laboral, de manera que, tradicionalmente, la tasa femenina era casi el doble que la masculina. La crisis actual ha ido equilibrando la situación por el empeoramiento del paro masculino, pero, aún hoy, el paro femenino supera en casi nueve puntos porcentuales al masculino. Esta situación es todavía más grave en el caso de las personas paradas que buscan su primer empleo, que en los espacios rurales alcanza el 16\%, y es especialmente grave en el grupo de menores de 25 años, aunque afecta también a algunas adultas de más de 45 años obligadas a intentar ingresar en el mercado laboral por las críticas condiciones económicas de la coyuntura actual.

Tampoco este momento crítico ha sido el mejor escenario para corregir, o paliar, el problema de la precariedad del trabajo femenino, ni se aprecia una mejora en las condiciones familiares en las que las mujeres rurales se desenvuelven en el mercado laboral. No se ha conseguido equilibrar la participación en las tareas domésticas, que siguen recayendo mayoritariamente sobre ellas, lo que incide negativamente en sus posibilidades de disponer de tiempo personal o para dedicar a su promoción profesional (figura 4).

\subsection{Los trabajos de las mujeres rurales}

Por lo que se refiere a la distribución sectorial de las ocupadas, mantiene los rasgos tradicionales relacionados con la segregación funcional por sexos. Las mujeres se concentran de forma absoluta en las actividades de servicios, mientras que los hombres tienen un abanico más amplio de posibilidades de inserción laboral en todas las ramas de actividad.

Menos de una quinta parte de los activos agrarios son mujeres y en el conjunto de las trabajadoras son solo una de cada 10 mujeres ocupadas en 2011 (figura 5). Poco o nada hemos avanzado en esta cuestión en la última década, y los esfuerzos por visibilizar las actividades agrarias de las mujeres no han tenido demasiado eco. 


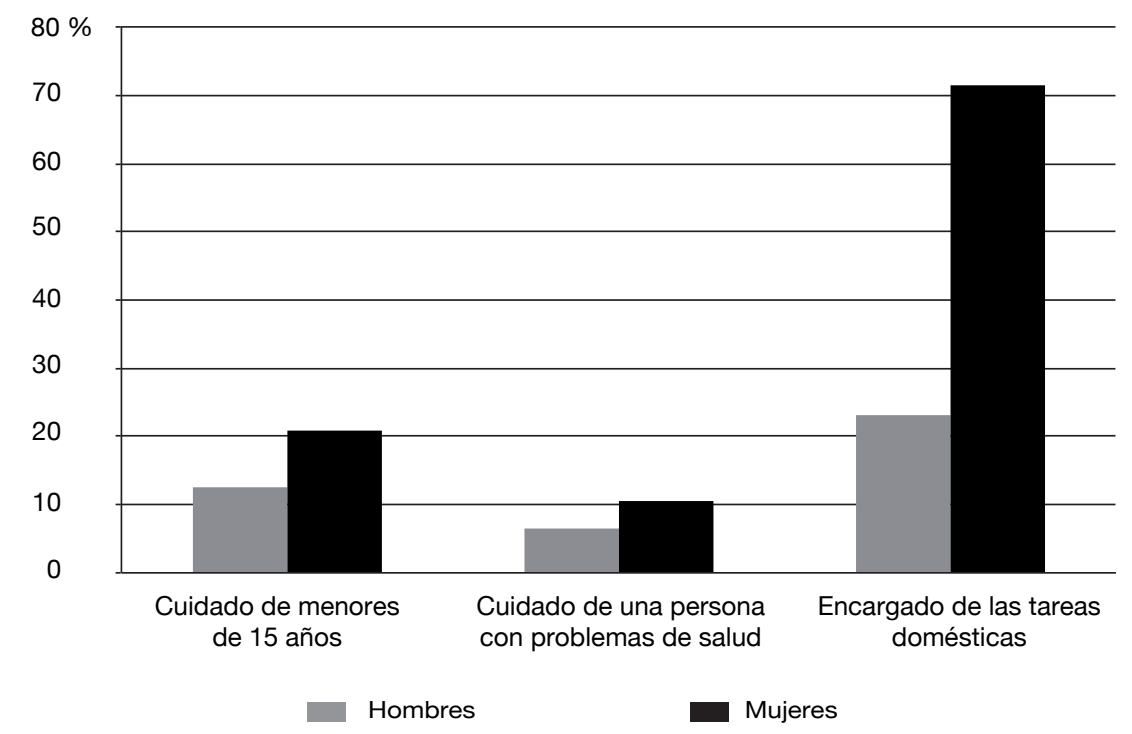

Figura 4. Tareas realizadas por las personas ocupadas en espacios rurales. Castilla y León, 2011.

Fuente: INE, Censo de Población 2011, microdatos. Elaboración: M. Alario.

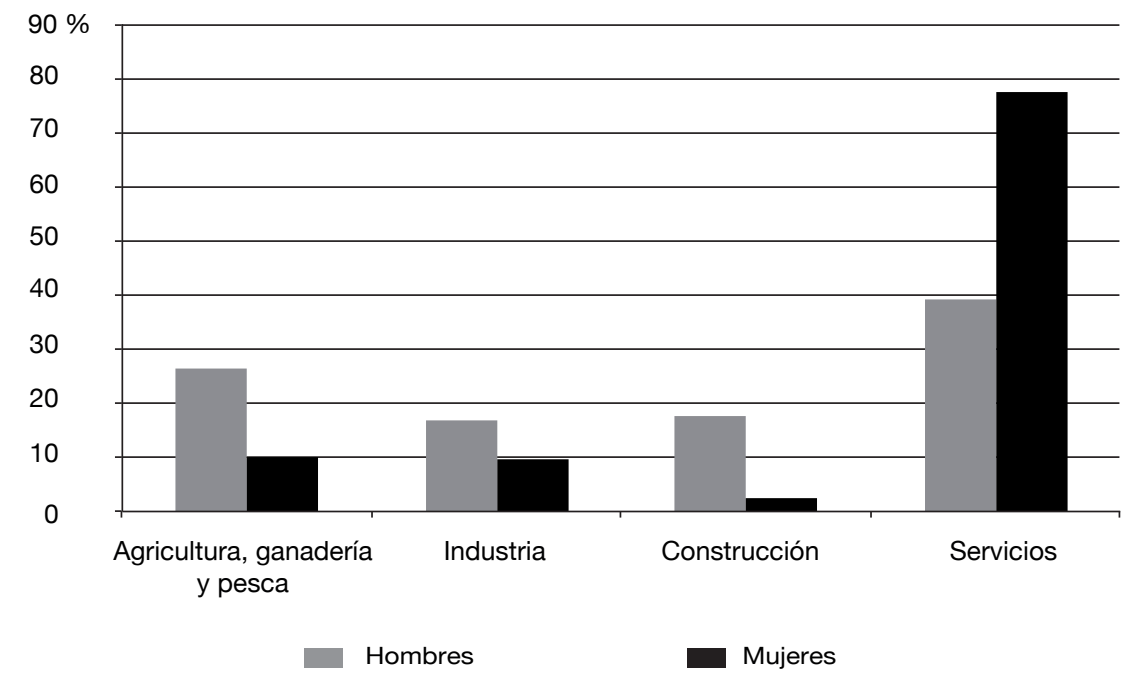

Figura 5. Estructura de las personas ocupadas. Espacio rural. Castilla y León, 2011. Fuente: INE, Censo 2011. Elaboración: M. Alario. 
Tabla 1. Resultados de los registros de titularidad compartida por comunidades autónomas

\begin{tabular}{lc}
\hline Comunidad Autónoma & N. ${ }^{\circ}$ de explotaciones \\
\hline Andalucía & 0 \\
Aragón & 6 \\
Canarias & 0 \\
Cantabria & 33 \\
Castilla La Mancha & 80 \\
Castilla y León & 7 \\
Cataluña & 3 \\
Comunidad Floral de Navarra & 3 \\
Comunidad Valenciana & 0 \\
Extremadura & 14 \\
Galicia & 0 \\
Islas Baleares & 0 \\
Madrid & 14 \\
Murcia & 13 \\
País Vasco & 1 \\
Principado de Asturias & 0 \\
La Rioja & 4 \\
Total & 13 \\
\hline
\end{tabular}

Fuente: Ministerio de Agricultura, Alimentación y Medio Ambiente: Registro continuo de titularidad compartida a 15 de abril de 2016.

La ley 35/2011 sobre titularidad compartida de las explotaciones agrarias es la última iniciativa normativa que se ha llevado a cabo para impulsar la visibilidad de las mujeres agricultoras, que permanecen en un segundo plano respecto a sus cónyuges en la titularidad legal de la explotación. Sin embargo, los escasos resultados, recogidos en la tabla 1 , no invitan al optimismo sobre su eficacia.

Aunque los de Castilla y León son los mejores en el conjunto nacional, su significado respecto a las mujeres que realmente comparten las responsabilidades de trabajo y gestión de las explotaciones agrarias es irrelevante. Unos resultados que no derivan de deficiencias normativas sino de sus dificultades de aplicación y de la falta de voluntad de las comunidades autónomas, a quien corresponde su responsabilidad.

Según el Censo Agrario de 2009, las mujeres que oficialmente figuran como ocupadas agrarias siguen manteniendo un perfil tradicional. Son mayores de 65 años en un $40 \%$ de los casos (frente al 26\% en los hombres), se concentran en explotaciones de agricultura convencional, con algo menor tamaño que las de los varones, y en un $26 \%$ de los casos no ostentan la jefatura de la explotación.

Los datos, lastrados por el peso de las explotaciones convencionales mayoritarias, encubren, sin embargo, algunos procesos nuevos que merece la pena destacar, como es la presencia de mujeres en los nuevos modelos de explotación - por ejemplo, la agricultura ecológica-, donde se detecta una significativa mayor presencia de mujeres jóvenes con formación en temas agrarios, que alcanza el $12 \%$ en agricultura convencional y el $46 \%$ en agricultura ecológica. 


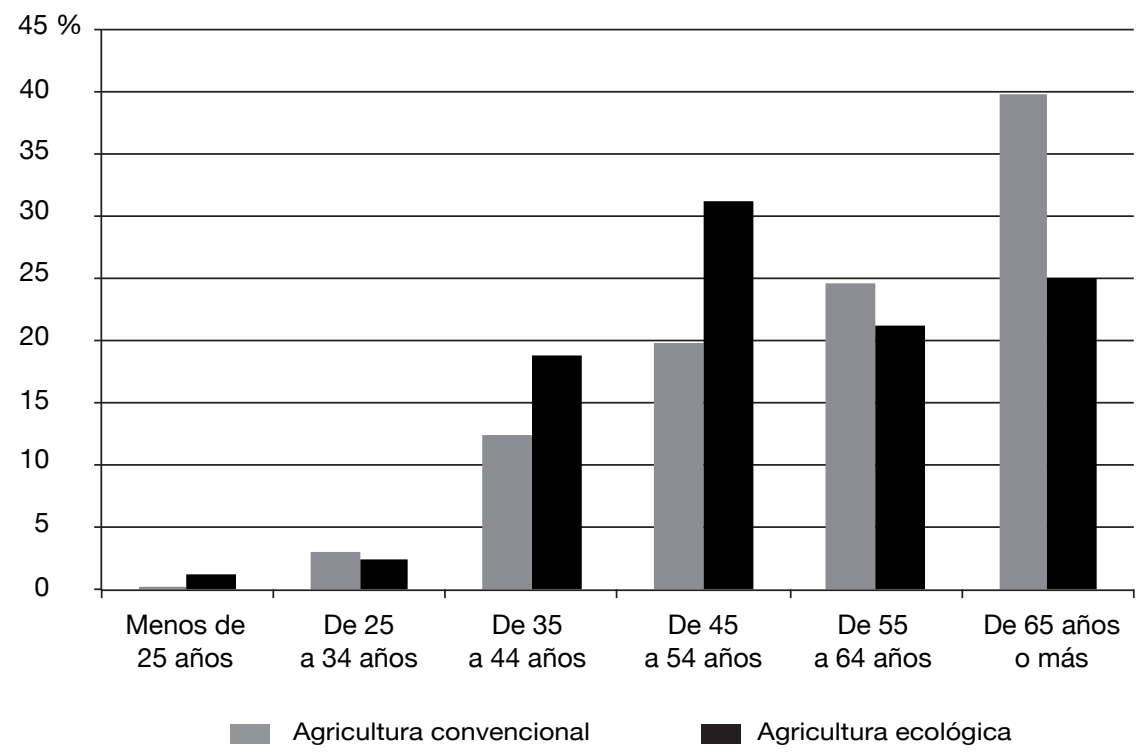

Figura 6. Agricultoras por edad y tipo de agricultura. Castilla y León, 2009.

Fuente: Censo Agrario 2009, microdatos. Elaboración: M. Alario.

Un modelo que emerge como nueva opción económica pero también en cierto modo como opción vital (Puleo, 2011; Cano, 2011).

En cuanto a la presencia de mujeres en las actividades industriales, solo es relevante en la industria agroalimentaria, especialmente en la manipulación y envasado hortofrutícola. Tiene una fuerte presencia en el sector del textil, pero hoy es una actividad casi marginal de la industria rural regional, por lo que su valor real como actividad laboral para las mujeres es escaso (figuras 7 y 8).

Por lo tanto, al igual que ocurre en el conjunto del territorio, la preeminencia de los servicios es absoluta en cuanto a destino laboral para las mujeres rurales de Castilla y León. El mantenimiento de los roles de género continúa inalterable en la última década, y siguen siendo los servicios a la población (comercio, hostelería, servicios personales, atención sanitaria y educativa...) los que concentran la mayoría absoluta de las trabajadoras. Entre ellos destacan, sin duda, los trabajos relacionados con la educación y la enseñanza.

Sin embargo, en un proceso que se inició hace dos décadas, las actividades relacionadas con el turismo rural se van consolidando no solo como alternativa laboral refugio para mujeres sino también como opción para el emprendimiento femenino, de forma que el $38 \%$ del total de promotores y el $51 \%$ de las personas físicas que figuran al frente de alojamientos de turismo rural en 2012 son mujeres. Cualitativamente es relevante su presencia en actividades profesionalizadas del turismo rural; así, entre las personas responsables de gerencia y dirección de los alojamientos de mayor nivel, las Posadas Reales, el 60\% eran 
N. ${ }^{\circ}$ de personas

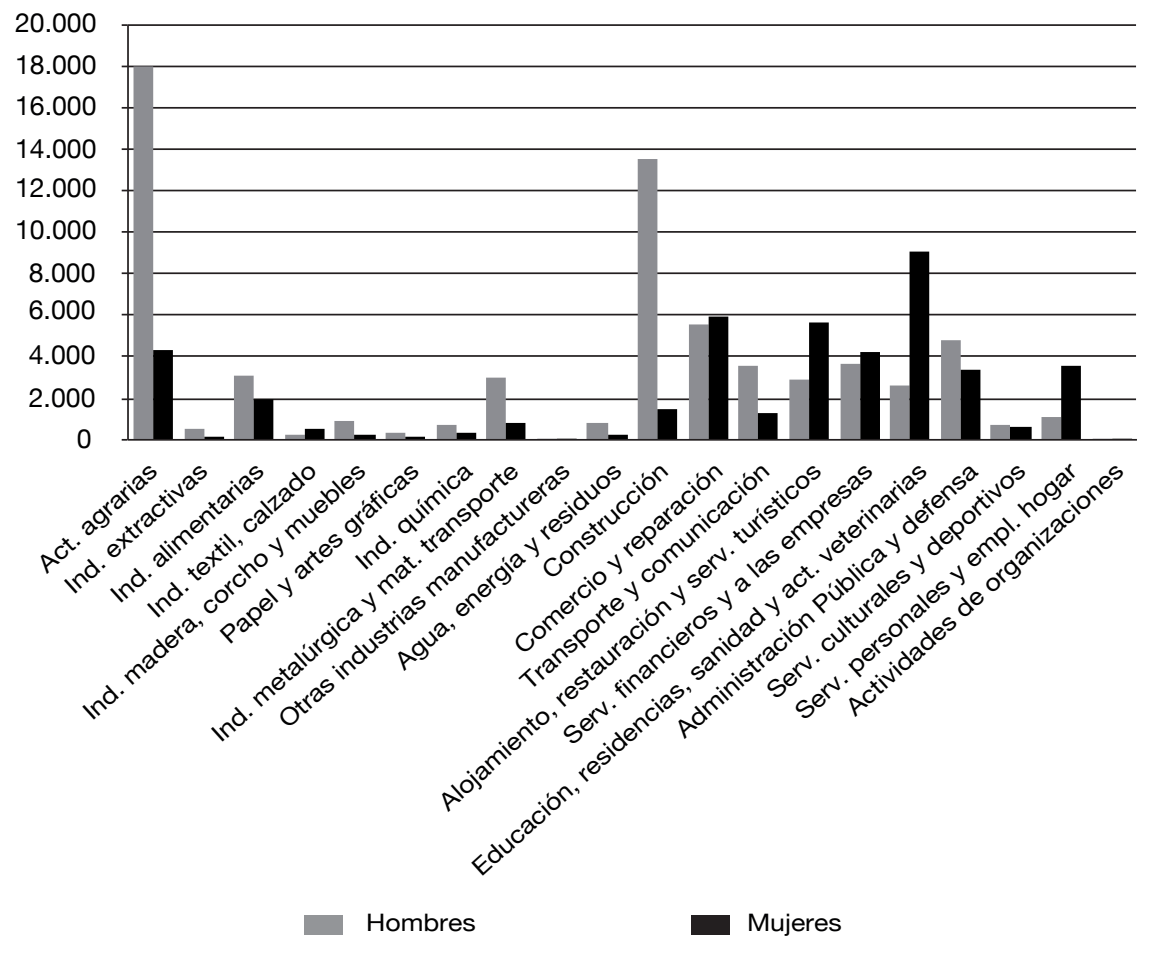

Figura 7. Población ocupada por sexos y actividad. Espacios rurales de Castilla y León, 2011. Fuente: INE, Censo de Población 2011 microdatos. Elaboración: M. Alario.

mujeres en 2012. Igualmente es significativa su presencia en las direcciones del resto de las Posadas y centros de turismo rural, verdaderas empresas que constituyen una opción real de negocio y vida y a la que va asociado un perfil distinto de trabajadora (Alario y Morales, 2012; Alario, 2014).

Las reducidas opciones que la estructura productiva de los espacios rurales castellanos y leoneses ofrece a las mujeres, junto con los incentivos públicos y el favorable clima social creado en torno al emprendimiento en las últimas décadas, las han impulsado a buscar soluciones personales a través de la puesta en marcha de iniciativas empresariales que han permitido su desarrollo profesional y de actividades productivas que aprovechan recursos locales (figura 9).

\subsection{La presencia femenina en el emprendimiento rural de Castilla y León}

Aunque no disponemos de datos completos que nos permitan cuantificar el proceso, es obvio que muchas de las iniciativas puestas en marcha por mujeres 


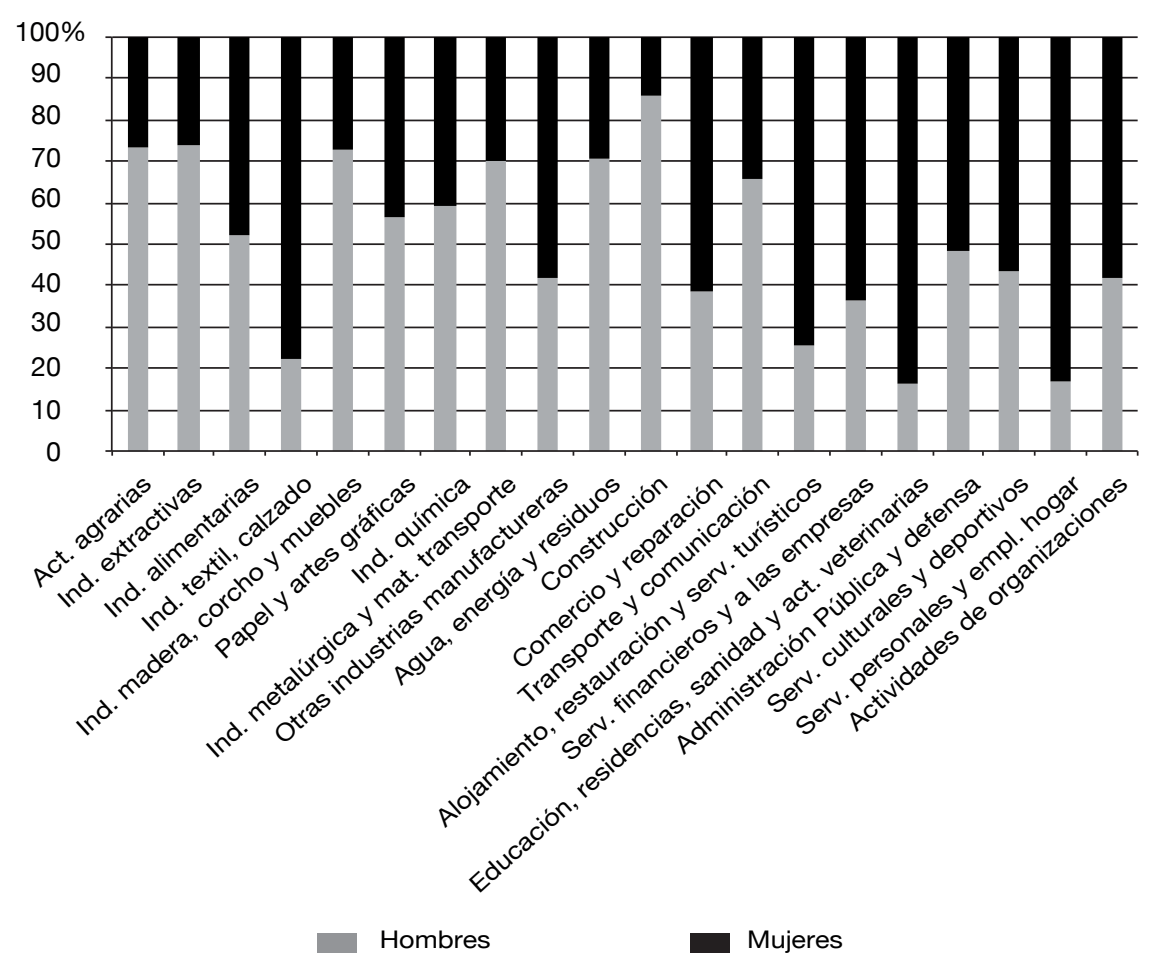

Figura 8. Estructura de la ocupación por sexos (\% en cada actividad). Espacios rurales de Castilla y León 2011.

Fuente: INE, Censo de Población 2011 microdatos. Elaboración: M. Alario.

en los espacios rurales de Castilla y León proceden de mujeres locales que buscan ingresos complementarios a las rentas familiares o necesitan autorrealizarse y buscar nuevas oportunidades. A pesar de su interés como manifestaciones de cambios en las actitudes de las mujeres rurales, en general no rompen con los estereotipos de género ni permiten una autonomía de rentas a las empresarias. Se sigue manteniendo la idea de que los ingresos femeninos, independientemente de su cuantía, constituyen rentas complementarias a las principales, siempre masculinas (Alario, 2004).

Estas características son las que ayudan a entender que muchas de las nuevas iniciativas estén relacionadas con actividades del ámbito doméstico u otras que las mujeres han asumido tradicionalmente y que ahora están reconocidas desde el punto de vista laboral. Son actividades como el turismo rural, la producción y comercialización de productos artesanos — mermeladas, repostería, cerámica...- o el cuidado y atención a la infancia y a personas mayores o en situación de dependencia (Alario, 2011). 


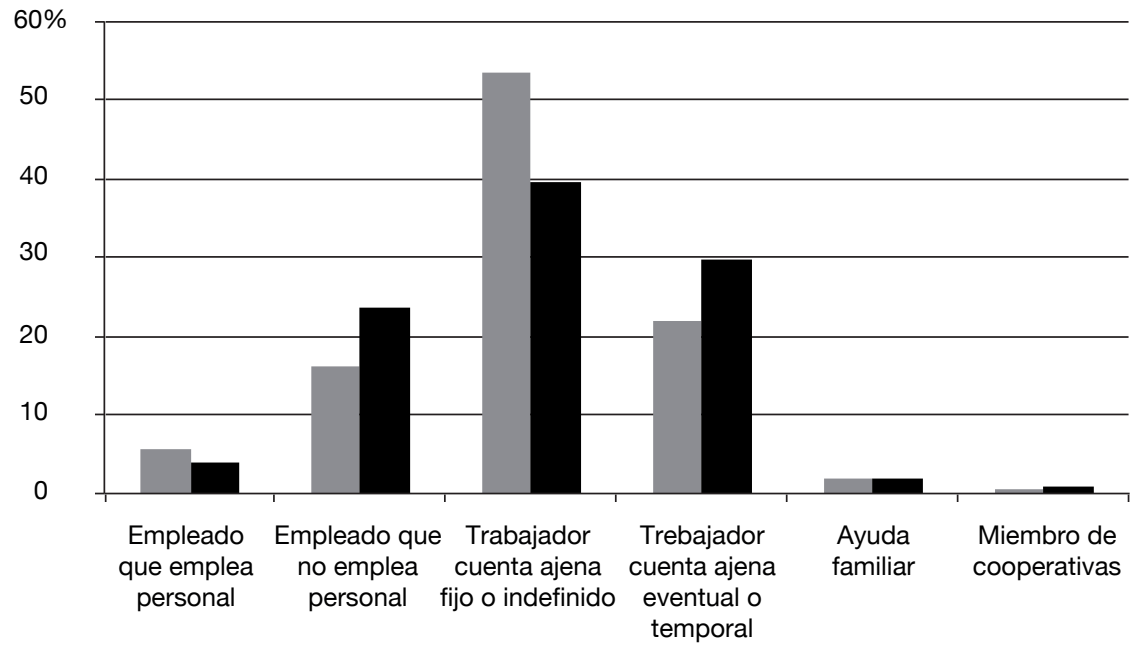

Figura 9. Situación profesional de mujeres residentes en espacios rurales. Castilla y León, 2001-2011.

Fuente: INE, Censo de Población 2001 y 2011, microdatos. Elaboración: M. Alario.

En los últimos años, sin embargo, se percibe el incremento de las iniciativas puestas en marcha por mujeres foráneas que han decidido instalarse en un medio rural para desarrollar en él su proyecto de vida (vital, personal, económico o laboral). Se trata de un colectivo - los neorrurales - que, de forma consciente, opta por un cambio de residencia acompañado generalmente de un cambio vital profundo, en busca no solo de un lugar diferente para vivir, sino también de un sistema de relaciones distintas, apoyadas en nuevas prioridades vitales y, en gran medida, en nuevas opciones laborales (Morales, 2015).

\subsection{Perfil de las nuevas pobladoras emprendedoras rurales}

Los cambios en la percepción social sobre los espacios rurales y sus potencialidades, así como la apuesta decidida por muchos de los programas de desarrollo rural y otros proyectos específicos, como Abraza la Tierra, han empezado a dar sus frutos y, en la última década, los espacios rurales, al igual que en el resto del país aunque con menor intensidad, han empezado a recibir nuevos pobladores. Una parte de ellos son personas que se trasladan a espacios rurales de entornos urbanos sin cambiar sus hábitos de vida y trabajo; son nuevos pobladores rurales en sentido estadístico pero su impacto sobre estos lugares es pequeño, ya que su grado de integración rural es bajo. Si acaso, su efecto es más transformador por la fuerza de los datos y arrastra a estos pueblos hacia dinámicas periurbanas. 
Otra parte, mucho más reducida cuantitativamente pero más importante para el mantenimiento de los espacios rurales, se corresponde con lo que se denomina neorrurales, personas que trasladan su residencia desde espacios urbanos a núcleos rurales, normalmente de pequeño tamaño y fuera del ámbito directo de influencia urbana (Pérez Rubio y Gurría Gascón, 2010). Sus razones son variadas, pero en todo caso conllevan una voluntad expresa de cambio de filosofía de vida.

El perfil de las neorrurales se corresponde con mujeres que anteriormente vivían en el medio urbano y en un momento determinado decidieron desarrollar su vida personal y laboral en el medio rural. De hecho, algunas de ellas continúan con la misma actividad profesional que realizaban en su lugar de origen, sin embargo, para otras trasladarse al medio rural ha supuesto una oportunidad, ya que han podido emprender actividades que en la ciudad resultaba más difícil desarrollar por cuestiones económicas, espaciales o personales. Aunque el contexto socioeconómico de los espacios rurales muestra un acceso limitado a los recursos humanos y financieros (Esparcia, 2014 en Pato, 2015), para estas mujeres priman otros motivos, como la calidad bucólica del medio rural, el ritmo lento de las áreas rurales respecto al acelerado ritmo de las ciudades (Smith, 2009 en Pato, 2015), el contacto con la naturaleza, la mejora de la calidad de vida, además de factores externos, como la capacidad de ayudar a crear nuevos empleos, contribuir a la mejora de la actividad económica, el crecimiento económico, la nueva riqueza en el espacio rural y la mejora de la vida de los residentes locales (Pato, 2015).

En conjunto, se trata de un grupo de mujeres entre los 25 y los 65 años de edad, en el que es mayoritario el grupo de edad entre los 25 y 45 , lo que nos indica un perfil de mujer joven y activa personal y laboralmente. Un $61 \%$ declara su situación de convivencia en pareja ( $44 \%$ casadas y $25 \%$ parejas de hecho o que conviven con su pareja) y un $23 \%$ son solteras. De las 73 mujeres encuestadas, el $53 \%$ han tenido hijos, de los cuales el 32\% aún viven en el hogar familiar, por lo que son mujeres que todavía cuidan de sus hijos y tienen que buscar soluciones para conciliar la vida familiar y laboral. Mayoritariamente proceden de grandes ciudades extrarregionales (Madrid y Barcelona) así como de urbes regionales (Burgos, Valladolid y Palencia, principalmente), y su destino fundamental son núcleos de muy pequeño tamaño, generalmente menores de mil habitantes.

Desde el punto de vista formativo y laboral, el $40 \%$ tiene estudios universitarios superiores, el $22 \%$ de posgrado y el $12 \%$ estudios universitarios medios, mientras que el $26 \%$ tiene estudios secundarios o estudios técnicos profesionales ( $10 \%$ y $16 \%$, respectivamente), lo que quiere decir que todas las mujeres encuestadas tienen un nivel de estudios medio-alto, aspecto que está íntimamente ligado a su situación laboral. El 63\% está trabajando, y a este grupo hay que sumar las que han contestado que se encuentran en otra situación, un $19 \%$, que se definen como emprendedoras, mientras que el 18\% restante se encuentran paradas (figura 10).

Vamos a centrar el análisis en ese 19\% de las encuestadas que han respondido que son emprendedoras, que en un momento determinado tomaron la decisión de emprender en el medio rural. 


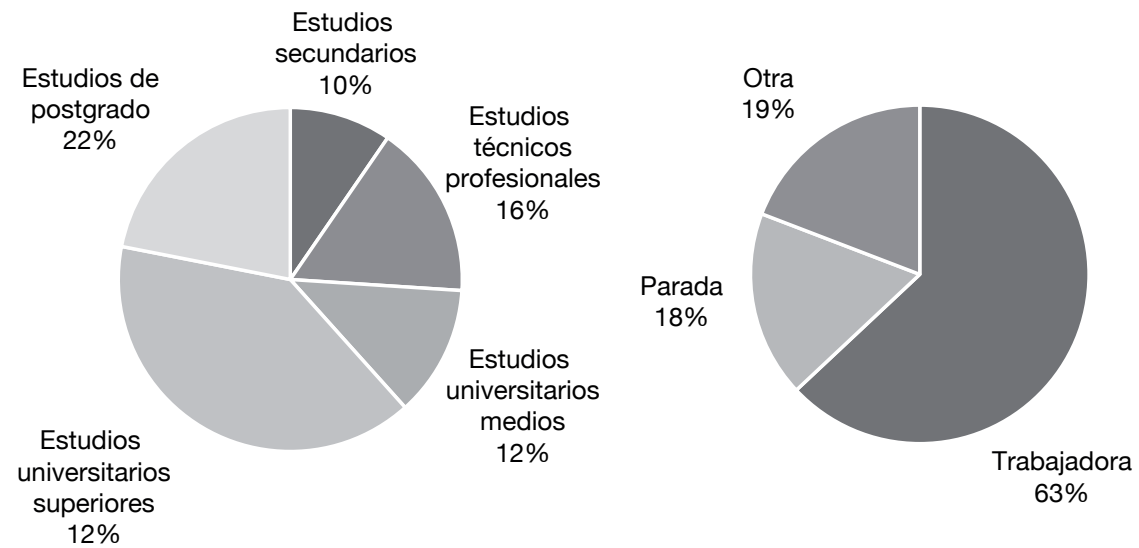

Figura 10. Nivel de estudios y situación laboral.

Fuente: Encuestas personales. Elaboración: E. Morales.

El perfil de las emprendedoras neorrurales sigue la línea del conjunto de las encuestadas. Mujeres entre los 25 y 45 años, que viven en pareja ( $43 \%$ casadas y $7 \%$ parejas de hecho) o solteras (36\%); el resto, separadas, divorciadas o viudas. El 36\% han tenido hijos, de los cuales el 14\% aún viven en el hogar familiar, lo que condiciona la conciliación de la vida familiar y laboral. Desde el punto de vista formativo y laboral no muestran mayores diferencias respecto al total de las neorrurales. De las emprendedoras, el $43 \%$ tiene estudios universitarios medios, seguidas de las que cuentan con estudios universitarios superiores (29\%), mientras que el 26\% tienen estudios secundarios o estudios técnicos profesionales ( $21 \%$ y $7 \%$, respectivamente), lo que quiere decir que todas las mujeres encuestadas tienen un nivel de estudios medio-alto que favorece el emprendimiento femenino (figura 11).

Por sectores económicos, destacan las respuestas de las mujeres dedicadas al sector servicios, no hay emprendimiento femenino en industria y tan solo dos han respondido que se dedican a la agricultura. Una de ellas, en concreto, se dedica a la agricultura ecológica, que al mismo tiempo complementa con otra actividad ligada a la producción artesana de los productos que cultiva: la elaboración de mermeladas, que es la base de su actividad. Esta emprendedora no solo se beneficia de la cercanía a la tierra y de la propia producción de la materia prima de manera ecológica, sino también de la mayor disponibilidad de espacio para elaborarla.

En el caso de los servicios se aprecia una cierta diversidad. Dominan las actividades emprendedoras ligadas al turismo, la sanidad, el comercio y la educación, pero también están presentes otras actividades, como la hostelería, la artesanía o el diseño (figura 12). Por ejemplo, en el caso de la educación cobran un papel importante las actividades de educación no formal, que, al mismo 


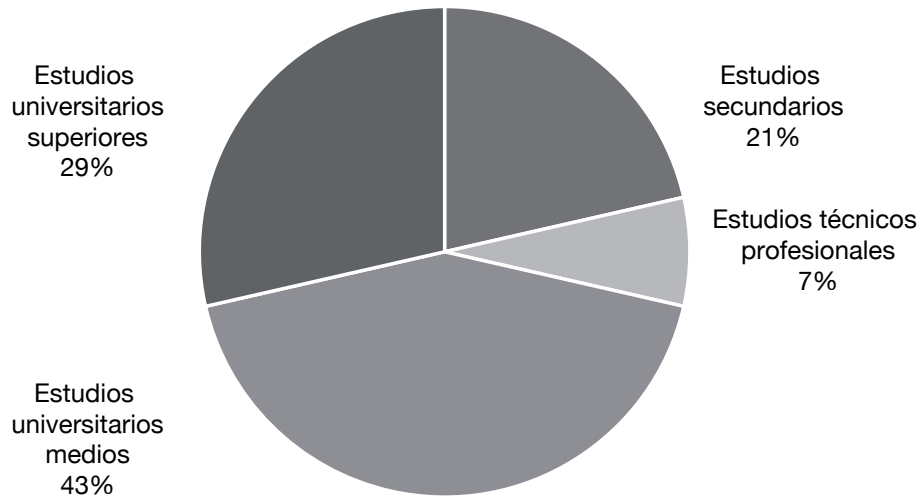

Figura 11. Nivel de estudios de las emprendedoras.

Fuente: Encuestas personales. Elaboración: E. Morales.

tiempo, combinan con otro tipo de actividades vinculadas al turismo. Encontramos más de un ejemplo en el que mujeres jóvenes, ingenieras de profesión, han puesto en marcha centros de turismo rural, casas rurales o albergues, en los que no solo ofertan alojamiento sino que también complementan esta actividad con cursos, formación y actividades ligadas a la naturaleza, como interpretación del paisaje, turismo ornitológico...

Algunas de estas mujeres han decidido empezar de nuevo una actividad, aunque otras han continuado con la actividad que realizaban en la ciudad. Así, podemos hablar de un doble perfil de emprendedoras: las que han continuado con su actividad de origen y muchas otras que han roto con su vida anterior (educadoras, logopedas, administrativas, amas de casa, operarias, etc.) para convertir lo que hasta el momento de la decisión del cambio consideraban su afición en su actividad laboral (clases de yoga, trabajo del cuero, rutas por la naturaleza...), con lo que inician un nuevo proyecto de vida laboral y personal. Por ejemplo, una de las emprendedoras encuestadas, ceramista de profesión, vio en el medio rural mayores facilidades para poder instalar su taller, ya que los locales resultaban más baratos que en la ciudad (en este caso, Madrid), pero también valoró que vivir en el medio rural le aportaba mayor tranquilidad e inspiración para poder crear nuevos trabajos.

De forma destacada se señala que un hecho que les ha permitido difundir su actividad o continuar con su cartera de clientes ha sido la conexión a internet, una herramienta clave a la hora de emprender en el medio rural, ya que permite difundir y ofertar la actividad que realizan en el medio rural a un mercado global.

Este perfil de emprendedora rural se adapta, en parte, a los tipos de emprendimiento a los que hace referencia el MARM en su estudio de 2013. Aunque son diferentes motivos los que han llevado a estas mujeres a emprender en el medio rural (figura 13), predominan los motivos laborales relacionados fun- 


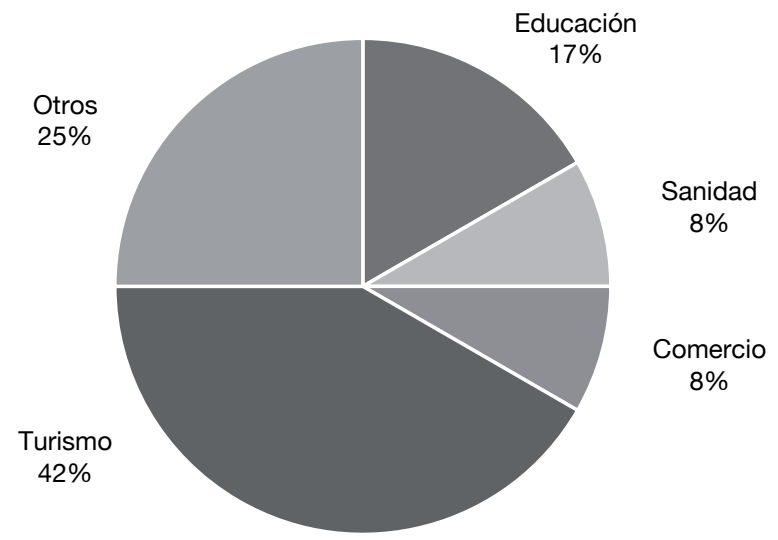

Figura 12. Actividades emprendidas en relación con el sector servicios.

Fuente: encuestas personales. Elaboración: E. Morales.

damentalmente con la posibilidad de aprovechar una oportunidad de inicio de una actividad emprendedora en segmentos poco desarrollados y con un fuerte potencial. A este tipo se vincula la apertura de negocios de turismo rural, talleres y tiendas de artesanía, manufactura y comercialización de productos elaborados (mermeladas, tef ${ }^{2}$, quesos, vino...), o, en muchos otros casos, de otro tipo de negocios, como la hostelería, actividades en la naturaleza (rutas de interpretación del paisaje, talleres de educación ambiental...), venta de productos naturales y masajes, clases de yoga y de pilates, negocios relacionados con el cuidado de niños o personas dependientes e incluso labores de investigación.

Junto a razones laborales, hay otros motivos que justifican su cambio de vida, entre los que predominan los personales y familiares. Los primeros se relacionan con la consideración de que en el medio rural el coste de vida es menor, y además este entorno les proporciona un cambio de estilo de vida, mayor tiempo libre, poder tener un espacio donde recrearse y disfrutar (tener un huerto y gallinas para autoabastecerse, animales de compañía....), lo que les permite al mismo tiempo poder organizar su vida personal y laboral y así conseguir una mayor conciliación familiar.

Entre los motivos familiares, que representan el 15\% de las respuestas, la decisión del cambio está relacionada con el crecimiento de la familia, ya que consideran que el medio rural es un entorno más adecuado y seguro para educar a sus hijos, a lo que se suma que la vida es más tranquila y permite distribuir mejor los tiempos.

Valoran el contacto directo con sus vecinos pero también con la naturaleza, de ahí que los motivos ambientales representen el 29\% de las respuestas. Estas

2. Cereal originario de Etiopía con un alto valor nutricional. 


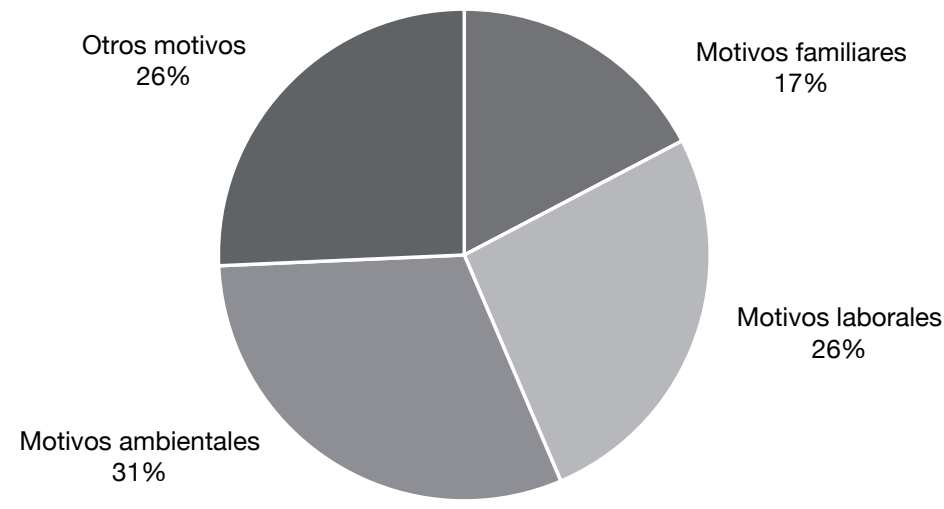

Figura 13. Principales motivos de cambio de las emprendedoras.

Fuente: Encuestas personales. Elaboración: E. Morales.

mujeres buscan un mayor contacto con la naturaleza, mayor calidad de vida, mejor calidad del agua y del aire, mayor espacio y menor contaminación y ruido.

Otros motivos que justifican la decisión del cambio de vida y optar por el emprendimiento se relacionan con salir del desempleo, a la par que se mejora la calidad de vida, la tranquilidad de vivir en el campo, vivir con menos estrés, la búsqueda de equilibrio para próximas generaciones, volver a las raíces...

Las impresiones que nos transmiten estas mujeres a través de las encuestas es que vivir en el medio rural les permite conciliar vida familiar y laboral, y muchas de ellas lo han conseguido gracias al inicio de una actividad emprendedora.

\section{Conclusiones}

Los cambios en el funcionamiento del mercado laboral impuestos por el incremento de la precariedad, la reducción de la estabilidad laboral y las rápidas transformaciones de perfiles profesionales y nichos laborales han provocado la emergencia de la opción del emprendimiento como alternativa que permite adaptarse a estos cambios, a la vez que facilita la inserción laboral de personas con condiciones específicas o, simplemente, con dificultades de integración en los mercados laborales tradicionales. La promoción del emprendimiento ha formado parte, pues, de todas las políticas públicas de promoción del empleo desde los años ochenta, con especial interés para la integración laboral de mujeres y jóvenes. Esta opción se considera de mayor relevancia, aún, en espacios rurales, donde las dificultades de creación de empleo asalariado son escasas y los sectores tradicionales de actividad se adecuan bien al desarrollo de pequeñas iniciativas de carácter emprendedor que crean pocos empleos asalariados pero que permiten el autoempleo a 
un número significativo de personas, lo que ayuda al mantenimiento de su dinamismo económico y social.

La dinámica rural de Castilla y León está dominada de manera clara por procesos de abandono y envejecimiento, en los cuales la salida selectiva de mujeres jóvenes tiene un papel fundamental. La difícil integración laboral en mercados estrechos reduce las opciones para las jóvenes bien preparadas que no encuentran acomodo en los pueblos. El fomento del emprendimiento ha sido una opción manejada por las políticas de desarrollo rural con la pretensión de favorecer la permanencia de esas mujeres e, incluso, atraer nuevos pobladores que ayuden a dinamizar esos territorios.

Es especialmente relevante el significado cualitativo de la llegada de nuevas mujeres emprendedoras, que, si bien no son capaces de corregir los desequilibrios históricos ni de cambiar las dinámicas demográficas y económicas, constituyen ejemplos de gran valor demostrativo en cuanto a las posibilidades de los espacios rurales regionales, ya que donde se instalan se convierten en referencia para una población envejecida y constituyen un ejemplo de las nuevas oportunidades que puede ofrecer el medio rural.

La vida en el pueblo es más tranquila, por lo que pueden gestionar con mayor facilidad su situación familiar y laboral, y a ello suman otros aspectos a los que ahora se pueden dedicar y que sin embargo en la ciudad no podían, como el cuidado de un huerto, de animales, mantener una relación más cercana con la población local, en muchos casos implicándose en la vida del pueblo fomentando la dinamización y la participación social. Estamos ante un modelo de nuevas pobladoras que, motivadas por la búsqueda de una mayor calidad de vida, han visto en el medio rural un espacio de oportunidades donde poder trabajar o emprender una actividad compatibilizando el bienestar familiar con el deseo personal de no dedicarse únicamente al trabajo doméstico y al cuidado de los hijos o personas dependientes.

Son en general mujeres con un nivel alto de estudios, que tienen naturalizada la opción del trabajo fuera del hogar y que ven en el emprendimiento una oportunidad para poder desarrollarse personal y profesionalmente.

La elección de un espacio rural determinado está ligada a las motivaciones personales que les han llevado a elegir espacios en contacto con la naturaleza, donde la vida es más tranquila y de mayor calidad. Consideran al mismo tiempo que el entorno es más adecuado y seguro para educar a sus hijos y, fundamentalmente, pueden dedicar tiempo no solo a su actividad profesional, sino también a disfrutar de la familia, al ocio y al tiempo libre.

\section{Referencias bibliográficas}

Aguilasocho Montoya, D. (2006). Familias y empresas. La creación de casas rurales en el marco del turismo rural. Tarragona:Universitat Rovira i Virgili. Tesis doctoral. <http://www.tdx.cat/handle/10803/8810> [consulta: 17 de agosto de 2014].

Andersson, K. et al. (2009). «Farmers, businessmen or green entrepreneurs? Producers of new rural goods and services in rural areas under urban pressure», Journal of Environmental Policy \& Planning, 11 (1), 29-43. 
Alario, M. (dir. y coord.) (2004). Las mujeres en el medio rural de Castilla y León. Valladolid. Consejo Económico y Social de Castilla y León. Informe técnico a iniciativa propia IIP1/04.

- (2011). Evolución de la inserción laboral de las mujeres en Castilla y León. Consejo Económico y Social de Castilla y León. Valladolid. Informe técnico a iniciativa propia IIP2/11.

Alario, M. y Morales, E. (2012). «Nuevos pobladores, nuevas funciones, nuevos paisajes: emprendedoras y turismo rural en Castilla y León». Investigando en Rural. Actas del XVI Coloquio de Geografía Rural de Sevilla, 53-62.

Bayllina, M. (2004). «Metodología para el estudio de las mujeres y la sociedad rural», Estudios Geográficos, 65, 5-28.

Baumgartner, D. et al. (2013). "What Kind of Entrepreneurship Drives Regional Development in European Non-core Regions? A Literature Review on Empirical Entrepreneurship Research», European Planning Studies, 21 (8), 1095-1127.

Cano, E. (2011). "El papel de las mujeres en la agricultura ecológica de Castilla y León». En: Vázquez Bermúdez, I. (coord.), Logros y retos. Actas de III Congreso Universitario Nacional "Investigación y género, 211-220.

Global Entrepreneurship Monitor (2013). Informe GEM Castilla y León. Director ejecutivo: Mariano Nieto. Universidad de León, CISE, Iberdrola, Fgulem.

- (2014). Informe GEM España. Red Española de Estudios Regionales, CISE, Santander Universidades, Fundación Rafael del Pino, Salamanca.

Karsten, L. y Meertens, D. (1992). «La geografía del género: sobre la visibilidad, identidad y relaciones de poder", Documents d'Anàlisi Geográfica, 19, 181-193.

LORDKIPANIDZE, M. et al. (2005). "The entrepreneurship factor in sustainable tourism development», Journal of Cleaner Production, 13 (8), 787-798.

MARM (2011). Diagnóstico de la igualdad de género en el medio rural. Madrid: Ministeriode Agricultura, AlimentaciónyMedio Ambiente

- (2013). Medio rural: trabajando en femenino. Madrid: Ministeriode Agricultura, Alimentación y Medio Ambiente.

Morales, E. (2015). Los nuevos pobladores en el medio rural de Castilla y León. Valladolid: Universidad de Valladolid. Tesis doctoral.

PAто, L. (2015). Rural entrepreneurship and innovation: some successful women's initiatives. Louvain-la-Neuve: European Regional Science Association (ERSA), 13.

Puleo, A. (2011). Ecofeminismo, para otro mundo posible. Valencia: Cátedra - Universidad de Valencia - Instituto de la Mujer.

RodrígueZ, M. ${ }^{a}$ R. (2013). «Estrategias de emprendimiento y emociones de mujeres empresarias: propuestas innovadoras en el contexto económico andaluz». XI Congreso Español de Sociología. <https://www.researchgate.net/publication/256474606_ Estrategias_de_emprendimiento_y_emociones_de_mujeres_empresarias_propuestas_innovadoras_en_el_contexto_economico_andaluz> [consulta: mayo 2013]

Ruiz, J. y GARCía, C. (2013). El fenómeno emprendedor y la convergencia norte-sur en Europa: evidencias del Observatorio GEM». Revista de Economía Mundial 35, 21-45.

Sabaté, A.; Rodríguez J. M. ${ }^{a}$ y Díaz; M. ${ }^{\text {a A. }}$ (2010). Mujeres, espacio y sociedad. Hacia una geografía del género. Madrid. Síntesis.

Sampedro, R. y Camarero Rioja, L. (2007). "Mujeres empresarias en la España rural. El sujeto pendiente del desarrollo». Revista Internacional de Sociología LXV, 48, 121-146. 